\section{(1) \\ HORIZONTES}

www.revistahorizontes.org
Horizontes. Revista de Investigación en Ciencias de la Educación Https://doi.org/10.33996/revistahorizontes.v3i12.86 octubre - diciembre 2019

Volumen 3 / No. 12 pp. 267- 283

\title{
Estrategia didáctica para desarrollar la lectura comprensiva en los estudiantes de primaria en Bolivia
}

\author{
Teaching strategy to develop comprehensive reading in elementary \\ students in Bolivia
}

\author{
Riosely Carolina Condo Isla \\ riocor8@gmail.com \\ Universidad Privada Domingo Savio, Bolivia
}

Recibido 5 de julio 2019 | Revisado ago-sep 2019 | Publicado 01 de octubre 2019

\section{RESUMEN}

La lectura complementa mediante la puesta en práctica lo aprendido, con ellas desarrollamos, descodificamos e interpretamos ideas. Por ello, el propósito de este artículo es mostrar el diseño de una estrategia didáctica para el fortalecimiento de la lectura comprensiva en los niños de primaria en Potosí, Bolivia. El proceso metodológico empleado en este estudio fue bajo el paradigma mixto cualitativo para recoger las interpretaciones del contexto trabajado, y cuantitativo para valorar las estadísticas que dieron pie a la recolección de la información. Los resultados arrojados a través del diagnóstico determinaron que era necesario buscar formas didácticas para desarrollar habilidades en la lectura compresiva en los niños de educación primaria objetos de estudio. Para finalizar, la lectura estudia los procesos implicados en la comprensión de un texto escrito, interviniendo ideas, experiencias previas del lector como también la imaginación correlacionadas a la imagen visual del texto.

Palabras clave: Lectura comprensiva; educación primaria; estrategia didáctica

\section{ABSTRACT}

Reading complements what has been learned by putting it into practice, with them we develop, decode and interpret ideas. Therefore, the purpose of this article is to show the design of a didactic strategy for strengthening comprehensive reading in primary school children in Potosí, Bolivia. The methodological process used in this study was under the qualitative mixed paradigm to collect the interpretations of the context worked, and quantitative to assess the statistics that gave rise to the collection of information. The results obtained through the diagnosis determined that it was necessary to look for didactic ways to develop skills in compression reading in primary school children under study. Finally, the reading studies the processes involved in the comprehension of a written text, intervening ideas, previous experiences of the reader as well as the imagination correlated to the visual image of the text.

Key words: Comprehensive reading; primary education; teaching strategy 


\section{INTRODUCCIÓN}

La lectura es una actividad importante y útil que las personas adquieren en su vida, entendiendo por ésta como un proceso complejo de decodificación e interpretación de signos. Una adecuada lectura se produce cuando los niños entre 6 a 7 años relacionan las imágenes con el cuento, establecen la relación entre los objetos que ha visto en la realidad y la representación de los mismos en las ilustraciones del texto, a partir de la imagen y del texto, los niños logran construir su propia representación, a crear una realidad en su mente. A través de la lectura comprensiva de cualquier nivel educativo, los niños amplían su vocabulario y aprenden frases cada vez más complicadas.

Es la interpretación de los signos y la decodificación que llevaran a los niños y niñas a comprender aquello que leen lo que permitirá adquirir el aprendizaje de todas las áreas académicas, permitiendo el acceso al conocimiento $\mathrm{y}$, en consecuencia, su enriquecimiento intelectual.

Es por ello, que desde el inicio de su aprendizaje, el alumno debe adquirir habilidades que le posibiliten la comprensión del texto escrito, mediante estrategias que deben estar en el sistema educativo nacional, regional y local, de la institución educativa, del aula, de los profesores de los alumnos y del contexto familiar, facilitando el desarrollo de ciertos procesos cognitivos, como el razonamiento la reflexión, la capacidad de análisis y síntesis.

La lectura cumple un rol fundamental en los niveles primarios donde los niños deben desarrollar habilidades de lectura comprensiva por lo que a medida que el estudiante va desarrollando la interpretación de ideas sobre un texto podrá crear, imaginar e interpretar. Pero si no establece habilidad de comprender lo que lee será muy poco la comprensión que se pueda obtener de un texto leído, es decir, leer comprensivamente es leer entendiendo a qué se refiere el autor.

Una persona que no sepa leer y lograr una lectura comprensiva no podrá estar preparada para el resto de su aprendizaje. Por eso, es importante que en una edad temprana, los niños desarrollen todo tipo de conocimientos logrando que se fomente la lectura y se empiece a hacer comprender a los estudiantes cómo funciona esta.

Curtis que es citado por González (2005) sostiene que: "En los últimos cursos de educación primaria las habilidades de comprensión sustituyen a las habilidades de descodificación como predictor del éxito lector." (p. 25). El autor afirma que las habilidades de descodificación son sustituidas por las habilidades de la lectura comprensiva donde ya no solo se decodifica, sino que se toman diferentes estrategias para que el niño comprenda lo que lee y que esto hará que el niño logre mayor éxito en la lectura.

Leer no es solo desarrollar hábitos de decodificación o de aumentar la velocidad de la lectura, sino que es un acto más complejo, implica ser más consciente en la esencia del texto interpretando de la manera adecuada. Estos procesos le permiten al estudiante adquirir futuros aprendizajes, por cuanto la lectura se considera como un proceso de construcción del sentido de un determinado texto, de acuerdo con sus actitudes individuales y sus conocimientos previos.

Sin embargo, se pudo observar que los niños del primer nivel primaria de la Unidad Educativa San Agustín de la Palca, Potosí, Bolivia no lograban comprender lo que leían, no reconocían, ni recordaban los hechos del cuento, saltaban las palabras al momento de leer, algunos empezaban a deletrear las palabras que no conocen o se les dificulta, se les olvida lo que leen cuando se les toma un repaso de lectura, y no lograban dar un criterio personal de la lectura realizada. 
En una entrevista realizada a la docente de aula, menciona que para los niños era complicado la comprensión de palabras simples entre pequeños párrafos, oraciones y frases que no les permite comprender lo que leían, como por ejemplo la profesora menciona que cuando se les plantaba a los niños que lean una oración como "mi mama me ama" y se les realiza preguntas como ¿quién te ama? ¿Qué hace tu mama? Los niños fracasan en su respuesta, también se les dificultaba identificar la relación existente entre la imágenes con la palabra o la relación existente entre lo que leen con la imagen, por lo que no existe una lectura comprensiva y que esto hace que no incrementar su vocabulario y obtengan bajo rendimiento académico en las materias de Ciencias Naturales, Ciencias Sociales, Religión, Educación Musical, Técnica y Tecnología las cuales requieren de atención, por parte de los niños para poder comprender y así aprender lo que la profesora les enseña.

Por todo lo expuesto se puede señalar que los niños de la Unidad Educativa San Agustín de la Palca ubicada en el área rural de la ciudad de Potosí presentan problemas en la lectura comprensiva, en este sentido nació la necesidad de desarrollar habilidades $y$ destrezas para comprender lo leído, interpretar, asimilar los textos para adquirir nuevos conocimientos.

La importancia a destacar en este estudio comprende a que la lectura se efectúa por las interpretaciones de los símbolos y la decodificación, la cuales permitirán al lector comprender el texto. Con ello se busca el desarrollo en los objetivos del lector, sus pensamientos, sus ideas y todo lo relacionado con los conocimientos previos. El proceso de lectura y su adecuado aprendizaje requieren el empleo de métodos que faciliten y aporten a la adquisición de esta habilidad. Por ende, en el presente artículo se destacará la estrategia didáctica para desarrollar la lectura comprensiva en los estudiantes de primaria de la Unidad Educativa San Agustín de la Palca ubicada en el área rural de la ciudad de Potosí en Bolivia, a fin de mejorar la lectura comprensiva, en concordancia para mejorar la calidad educativa, además de fortalecer en los niños un aprendizaje que les permita adquirir conocimientos en su proceso educativo.

\section{MÉTODO}

Con relación al aspecto metodológico usado para lo que fue el desarrollo de este estudio, fueron asumido, tanto el enfoque cualitativo y cuantitativo, porque se llevó a cabo en la realidad del contexto como sucede, interpretando situaciones de acuerdo con las personas implicadas u objeto de estudio, se recabaron datos mediante los instrumentos dentro del diagnóstico, las conclusiones y las recomendaciones para realizar un análisis de los resultados obtenidos, y es de un enfoque cuantitativo porque apoyo a la presente investigación a obtener datos de forma numérica, de los resultados que se obtuvieron a partir de los instrumentos aplicados, permitiendo la comprensión y exactitud de los resultados. Con relación al diseño, se usó documental para realizar la elaboración de los principales fundamentos teóricos relacionados con la lectura y la lectura comprensiva, para ello, la recopilación de la información se realizó mediante instrumentos que permitieron obtener los referentes del tema objeto de este estudio, también fue de campo debido a que se trabajó con las docentes y con los niños directamente para recabar la información de las deficiencias en la lectura comprensivas.

\section{RESULTADOS Y DISCUSIÓN}

En este apartado se detalla la estrategia didáctica diseñada para dar cumplimiento al 
objetivo que se planteó en la investigación, relacionado con la comprensión lectora de los estudiantes de educación primaria de la Unidad Educativa San Agustín de la Palca ubicada en el área rural de la ciudad de Potosí en Bolivia, así mismo los talleres educativos y los rincones de aprendizaje con su respectiva planificaciones

\section{Estructuración de la estrategia didáctica}

Para la estructuración de la estrategia didáctica acerca de la comprensión lectora se utilizó el modelo planteados por Soto (2013) en relación algunos ítems, los cuales se describen a continuación:

- Objetivo: Determinó lo que el niño debió reconocer, comparar, relacionar, aplicar, comprender, explicar, analizar, interpretar, diferenciar al finalizar el ciclo del curso.

- Contenido: fueron los procedimientos de conceptos y actitudes que fueron desarrollados para alcanzar los objetivos del área o materia. Tuvo un carácter mediador e instrumental para conseguir los objetivos planteados, y fueron articulados en unidades didácticas, secuencias, núcleos de aprendizaje individuales o grupales, proyectos, diálogos exposiciones y debates.

- Metodología: Con este se construyó la organización del proceso de enseñanza y aprendizaje que desarrolló las decisiones tomadas sobre la selección de contenidos, organización de contenidos, tipo de actividades, agrupamiento del alumno, recursos a utilizar, organización de espacios y tiempos, evaluaciones. Incluyó métodos, estrategias, actividades y recursos.

- Evaluación: Permitió evaluar el conocimiento adquirido durante todo el proceso de aprendizaje, con el objetivo de verificar el rendimiento académico. No solo valora los resultados académicos del alumno, sino que determina que se enseña, cómo se enseña, que aprende y cómo se aprende, proporcionando información relevante al profesor, alumno y a los padres de familia sobre el proceso de enseñanza y aprendizaje.

Parte de las actividades que se realizaron fue el taller educativo y el rincón de aprendizaje.

\section{Taller educativo}

Para la construcción de la propuesta del taller se tomó en consideración las fases planteadas por Betancourt, (2007):

\section{Fases del taller educativo}

- Las fases son: iniciación, preparación, explicación, interacción, presentación y evaluación.

- Iniciación dejan en claro quiénes son los participantes y lo que se debe hacer.

- Objetivo se dan a conocer las diferentes tareas, los proyectos a emprender y lo que se espera al final del taller.

- Descripción y materiales se amplían los procesos a realizar y de asignar los materiales que servirán para la producción.

- Interacción Existen dos actores fundamentales en este modelo el participante y el profesor o facilitador quienes realizarán tres pasos fundamentales para el desarrollo del taller educativo el diagnóstico, el desarrollo del tema y la aplicación del tema que facilitarán el desarrollo del taller educativo.

- Presentación y Evaluación consiste en compartir con los demás lo producido y posteriormente se discuten los 
resultados a fin de reforzar 0 retroalimentar la propuesta.

\section{Rincón de aprendizaje}

\section{Fases del rincón de aprendizaje}

- La organización y distribución de los rincones de aprendizaje en el aula, deben ser situadas en función del espacio con que se cuenta con sus respectivos materiales.

- Los horarios de trabajo o juego en los rincones de aprendizaje, lo establece la educadora, la duración de las actividades dependerá de la edad del niño, pueden ser de 30 a 45 min.

- El niño o grupo de niños visitarán los rincones de aula de acuerdo a su libre elección y luego irá rotando.

- Las actividades o juegos serán planteados de acuerdo a los objetivos educativos o a la propuesta metodológica de los docentes, propuesta infantil, talleres, proyectos entre otros.

- Concluido con las diferentes estrategias didácticas a continuación se verán los principios y la contribución de otras ciencias a la estrategia didáctica.

\section{Contribuciones y principios de otras ciencias a la estrategia didáctica}

Para la estructuración de la propuesta se toma en consideración los planteamientos pedagógicos relacionados con el proceso de enseñanza y aprendizaje en la construcción de la estrategia didáctica estas ciencias son la psicología, pedagogía y la didáctica.

\section{Desde la psicología}

Para definir este principio se realizará un análisis del principio de la psicología Gervilla, (2006).
- Principio de la relación concienciaactividad: este principio buscará la participación activa, creadora de los niños, desarrollar la inteligencia crear un ambiente alegre y de confianza, logrando así que éstos comprendan el texto a pesar de las dificultades que presenten se logre estimule la seguridad personal de cada niño para alcanzar los objetivos planteados mediante la motivación.

- Principio del desarrollo de la psiquis: Este principio trabajó las relaciones conductuales en la sociedad, siendo que el aprendizaje seda a través de la práctica donde los niños aprenden observando a otras personas, por lo que se plantea diferentes estrategias donde el alumno se relaciona con su entorno y desarrolla nuevos conocimientos emitiendo opiniones, decisiones que le permita comprender los textos y adquirir nuevos conocimientos.

- Principio de la unidad teóricapráctica: En la propuesta a partir de este principio se realizarán diferentes estrategias donde los niños no solo se queden con la teoría, sino que en base a esa teoría se realicen prácticas logrando que asimilen o comprendan lo que se les enseñe y que esto les permite tener un aprendizaje significativo.

\section{Desde la pedagogía}

En este estudio se principio de la pedagogía de Paymal, (2008), el cual se describe a continuación:

- Principio de la enseñanza activa: En el diagnóstico este principio aportó la realización de estrategias donde los niños construyan su propio conocimiento, donde el niño debe desarrollar habilidades de búsqueda, selección y 
análisis que le permita adquirir conocimientos a través de las diferentes metodologías activas, el niño conseguirá aprender de manera automática en base a su edad y ritmo de aprendizaje donde el niño será un participante activo.

- Principio de la enseñanza repetitiva: en la propuesta este principio fue empleado como estrategia en el aprendizaje repetitivo, ya que los niños necesitan retener palabras que no comprenden dentro de una lectura de un texto, hasta que logran retenerlo en la memoria y sean capaces de comprenderlo $\mathrm{y}$ analizarlo.

- Principio de la enseñanza cooperativa: En la propuesta fue tomado como una estrategia que permitirá la interacción entre las personas que lo rodean y así fomentar la cooperación, colaboración y solidaridad entre los alumnos, por lo cual no se debe tomar en cuenta la influencia que tienen los compañeros de clase cuando se participa en los grupos de trabajo, donde los alumnos aprenden mediante la interacción que existe entre ellos.

\section{Desde la didáctica}

En este estudio se realizó un análisis del principio de la psicología de Gervilla, (2006), el cual destaca:

- Principio de comunicación: Dentro de la propuesta la comunicación fue fundamental para realizar un proceso de aprendizaje donde los niños transmitan sentimientos, ideas y en base a esto se realice nuevos conocimientos. Que le permitirá al estudiante dar a conocer las cosas que entiende o las cosas que no ha comprendido sobre un texto u otro tema siendo así que la capacidad para comunicar es vital para lograr cualquier objetivo.

- Principio de actividad: En la propuesta se empleó este principio de actividad siendo que es un proceso fundamental en todo proceso educativo, facilitando que el niño aporte ideas mediante las tareas que realicen y que no solo se realice lo que propone el maestro, sino que lo importante es que el niño logre una participación activa.

- Principio de creatividad: En la propuesta este principio ayudó a realizar actividades mediante la imaginación donde los niños logren desarrollar su creatividad mediante la realización de tareas creativas como la creación de un cuento, para que un niño logre ser creativo y a la vez imaginativo, por lo que se plantean diferentes métodos que permitan a los niños desarrollar su creatividad.

Después de haber dado a conocer los diferentes principios y su relación con la propuesta a continuación muestra el programa de estimulación de la lectura comprensiva.

\section{Elaboración de una estrategia didáctica para desarrollar la lectura comprensiva}

Para la realización de la propuesta se dio a conocer los objetivos, el contenido, la metodología y la evaluación de toda la propuesta y las actividades planteadas para el desarrollo de la lectura comprensiva.

\section{Objetivo de la estrategia}

Elaborar una estrategia didáctica para el desarrollo de la lectura comprensiva en los niños del 1 "A" de nivel primaria de la Unidad Educativa San Agustín de la Palca ubicada en 
el área rural de la ciudad de Potosí mediante un conjunto de actividades propuestas por el psicopedagogo.

\section{Contenido de la propuesta}

- Reconocer los diferentes personajes del texto

- Reconocer las cualidades de los personajes del texto

- Señalar a los personajes, objetos lugares del cuento

- Resumen de cuentos, leyendas, historias entre otros

- Interpretar y recuperar el mensaje que contiene un cuento

- Identificar la secuencia de los hechos ocurridos de un texto leído mediante las imágenes.

- Realizan comentarios sobre el contenido del texto a partir de la imagen central del cuento.

- Realización de opiniones y preguntas sobre lo leído

- lectura en voz alta y lectura silenciosa

\section{Actividades de la propuesta}

Las actividades que fueron empleadas para el desarrollo de la lectura comprensiva son: taller educativo y rincón de aprendizaje.

\section{Evaluación de la propuesta}

Para la evaluación de la propuesta y conocer la asimilación alcanzada en base a las diferentes actividades planteadas sobre la lectura comprensiva, tanto para los niños, profesores y padres de familia se realizó una feria expositiva.
Como se ha mencionado anteriormente las actividades que se desarrollaron fueron el taller educativo y el rincón de aprendizaje, además de dos (2) talleres dirigidos a los padres de familia (ver cuadro 1) que se efectuó cada fin de semana durante el tiempo que se llevó acabo el estudio, tres 3 talleres a los profesores (Cuadro 2) que se realizó cada inicio de semana, para ello, se elaboró una evaluación sobre los conocimientos que tienen los profesores acerca de la lectura comprensiva, y al finalizar los talleres. También se realizó la evaluación de cierre a fin de conocer las impresiones de los profesores relacionadas con sus conocimientos sobre el desarrollo de la lectura comprensiva en los estudiantes.

Por otra parte, fueron planteados seis (6) talleres educativos dirigidos a los niños, los cuales se efectuaron uno cada semana sobre los temas determinado y planteados en el programa curricular en la institución educativa, además, fue realizado uno de los rincones de aprendizaje del mismo tema del que se dio el taller, todos los talleres mantuvieron una secuencia con el objetivo de reforzar lo aprendido en el taller anterior educativo.

El total de actividades entre talleres y rincón educativo educativos fueron (11) de los cuales se sostuvieron seis (6). Los rincones de aprendizaje estuvieron exclusivamente dirigidos a los niños existiendo tres rincones de aprendizaje, en cada rincón se plantea diferentes temáticas para el desarrollo de la lectura comprensiva en base a las dificultades que tienen los niños, cada rincón de aprendizaje se realizará 1 por semana. (Ver cuadro $3,4,5,6,7,8,9,10,11,12$ ). 
Cuadro 1. Desarrollo de los talleres educativos para los padres de familia

\section{Taller}

El hogar y la lectura 1

El hogar y la lectura 2

\section{Objetivo}

Conocer los factores que influyen en la lectura comprensiva a través de actividades organizadas por el psicopedagogo dirigidas para los padres de familia.

Reconocer la importancia que tiene el apoyo familiar en el desarrollo de la lectura comprensiva en el niño planificada por el facilitador a través de dinámicas participativas dirigida a los padres de familia

Cuadro 2. Desarrollo de los talleres educativos para los profesores

\section{Taller}

El tesoro de la lectura 1

El tesoro de la lectura 2

El tesoro de la lectura 3

\section{Objetivo}

Adquirir conocimientos sobre la lectura comprensiva a través de actividades participativas organizada por el psicopedagogo dirigida a los profesores.

Adquirir conocimientos sobre las estrategias de lectura comprensiva organizadas por el facilitador a través de actividades participativas dirigidas a los profesores.

Aplicar los conocimientos de estrategias de lectura comprensiva organizadas por el facilitador través de actividades participativas para los profesores. 
Cuadro 3. Desarrollo de los talleres educativos para los niños

\begin{tabular}{cl}
\multicolumn{1}{c}{ Taller } & \multicolumn{1}{c}{ Objetivo } \\
\hline La luz de la lectura comprensiva 1 & $\begin{array}{l}\text { Identificar los personajes de un cuento a través de } \\
\text { una lectura para los niños planificadas y elaboradas } \\
\text { por el facilitador en base a tareas y actividades } \\
\text { participativas. }\end{array}$ \\
\hline La luz de la lectura comprensiva 2 & $\begin{array}{l}\text { Reconocer las cualidades de los personajes de un } \\
\text { cuento a través de una lectura para los niños } \\
\text { planificadas y elaboradas por el facilitador en base } \\
\text { a tareas yactividades participativas. }\end{array}$ \\
\hline La luz de la lectura comprensiva 3 & $\begin{array}{l}\text { Señalar a los personajes y lugares de un cuento a } \\
\text { través de una lectura para los niños planificadas y } \\
\text { elaboradas por el facilitador en base a tareas y } \\
\text { actividades participativas. }\end{array}$ \\
\hline La luz de la lectura comprensiva 4 & $\begin{array}{l}\text { Elaborar resúmenes de cuentos, leyendas, historias } \\
\text { a través de lectura para niños planificadas y } \\
\text { elaboradas por el facilitador en base a tareas } \\
\text { actividades. }\end{array}$ \\
\hline La luz de la lectura comprensiva 5 & $\begin{array}{l}\text { Reconocer el mensaje que contiene un cuento a } \\
\text { través de una lectura para los niños planificadas y } \\
\text { elaboradas por el facilitador en base a tareas y } \\
\text { actividades participativas. }\end{array}$ \\
\hline la luz de la lectura comprensiva 6 & $\begin{array}{l}\text { Identificar la secuencia de los hechos ocurridos de } \\
\text { un texto leído mediante imágenes a través de una } \\
\text { lectura para los niños planificadas y elaboradas por } \\
\text { el facilitador en base a tareas y actividades } \\
\text { participativas. }\end{array}$ \\
\hline
\end{tabular}

\section{Rincón del cuento 1}

Cuadro 4. Reconociendo a los personajes de un cuento

\begin{tabular}{|c|c|c|c|c|}
\hline Actividades & Descripción & Materiales & Tiempo & Responsable \\
\hline $\begin{array}{l}\text { Les presentamos } \\
\text { aaaa.... }\end{array}$ & $\begin{array}{l}\text { Se les presentará a los niños } \\
\text { imágenes de dibujos } \\
\text { infantiles clásicos, como ser } \\
\text { pato Donald, caperucita roja } \\
\text { entre otros Para que en } \\
\text { base a esos personajes } \\
\text { cuenten que es lo que } \\
\text { recuerdan de esos cuentos. }\end{array}$ & $\begin{array}{l}\text { Láminas con las fotos } \\
\text { de los personajes }\end{array}$ & $15 \min$ & Psicopedagogo \\
\hline $\begin{array}{l}\text { Creando una } \\
\text { lámina }\end{array}$ & $\begin{array}{l}\text { Todos los niños pegaran las } \\
\text { fotografías de los } \\
\text { personajes clásicos que se } \\
\text { les dio, para luego crearán } \\
\text { una historia entre todos en } \\
\text { base a las características de } \\
\text { los personajes de las } \\
\text { fotografías }\end{array}$ & $\begin{array}{l}\text { imágenes con las } \\
\text { fotos de los } \\
\text { personajes, hojas } \\
\text { pliegue y pegamento }\end{array}$ & $20 \mathrm{~min}$ & Psicopedagogo \\
\hline
\end{tabular}




\section{Rincón del cuento 2}

Cuadro 5. Reconociendo a las cualidades de los personajes

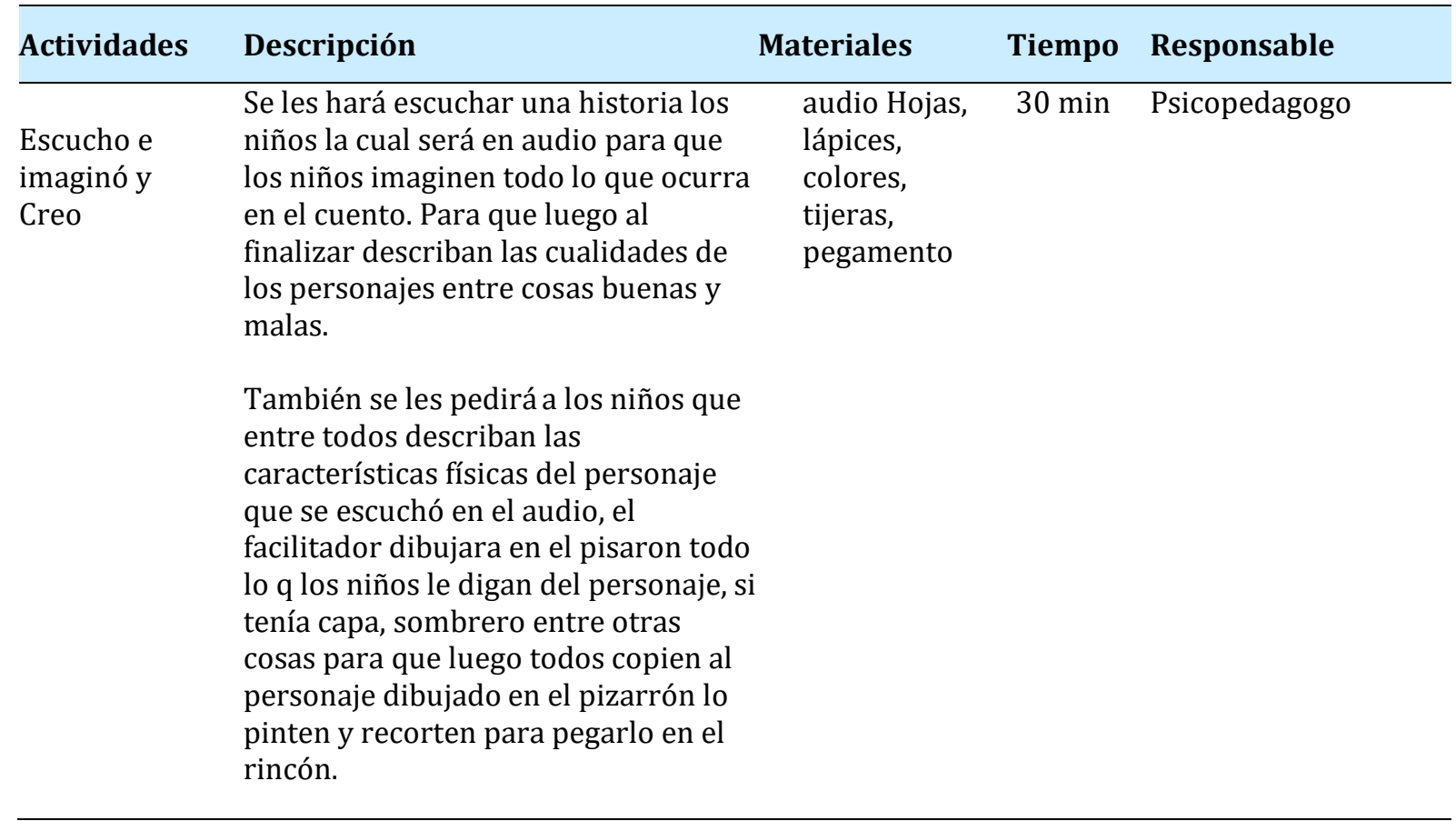

\section{Rincón del cuento 3}

Cuadro 6. Señalando a los personajes y lugares de un cuento

\begin{tabular}{|c|c|c|c|c|}
\hline Actividades & Descripción & Materiales & Tiempo & Responsable \\
\hline \multirow[t]{2}{*}{$\begin{array}{l}\text { Creando mi } \\
\text { cuento }\end{array}$} & $\begin{array}{l}\text { Se les presentará a los niños una } \\
\text { gráfica de un bosque donde están } \\
\text { los tres gigantes y blanca }\end{array}$ & $\begin{array}{l}\text { Hojas con el } \\
\text { cuento y } \\
\text { gráfica, lápices }\end{array}$ & $20 \mathrm{~min}$ & Psicopedagogo \\
\hline & $\begin{array}{l}\text { Nieves. Este gráfico contendrá la } \\
\text { iniciación del cuento, para que los } \\
\text { niños en sus propias palabras sigan } \\
\text { realizando el cuento. } \\
\text { Guiándose por la imagen y la } \\
\text { pequeña iniciación del cuento. }\end{array}$ & & & \\
\hline $\begin{array}{l}\text { Contando mi } \\
\text { cuento }\end{array}$ & $\begin{array}{l}\text { Cada niño contará el } \\
\text { cuento que creó } \\
\text { anteriormente, con la } \\
\text { ayuda del facilitador. }\end{array}$ & & $15 \min$ & Psicopedagogo \\
\hline
\end{tabular}




\section{Rincón del cuento 4}

Cuadro 7. Resumiendo, cuentos, leyendas, historias y más

\begin{tabular}{lllll}
\hline \multicolumn{1}{c}{ Actividades } & Descripción & Materiales & Tiempo & Responsable \\
\hline $\begin{array}{l}\text { Títeres de } \\
\text { dedos }\end{array}$ & $\begin{array}{l}\text { Se presentará a los niños } \\
\text { un teatro donde los } \\
\text { personajes son títeres las } \\
\text { cuales el facilitador se los } \\
\text { colocara a cada dedo } \\
\text { para realizar la historia } \\
\text { de un cuento. }\end{array}$ & $\begin{array}{l}\text { Títeres para } \\
\text { dedo }\end{array}$ & $20 \mathrm{~min}$ & Psicopedagogo \\
Mi resumen & $\begin{array}{l}\text { Los niños realizarán un } \\
\text { resumen escrito de todo lo } \\
\text { que ocurrió en el teatro y } \\
\text { dibujaran a los personajes } \\
\text { del cuento para luego } \\
\text { pegarlas en el rincón }\end{array}$ & $\begin{array}{l}\text { Hojas, } \\
\text { pegamento }\end{array}$ & & \\
& & & \\
\end{tabular}




\section{Rincón teatral 5}

Cuadro 8. Recuperando el mensaje que contiene un cuento

\begin{tabular}{|c|c|c|c|c|}
\hline Actividades & Descripción & Materiales & Tiempo & Responsable \\
\hline \multirow[t]{2}{*}{ La historia de la bruji } & $\begin{array}{l}\text { i Se realizará un teatro de } \\
\text { títeres, sobre la bajita, al } \\
\text { finalizar el teatro los } \\
\text { niños entre todos } \\
\text { analizarán cuál fue el } \\
\text { mensaje central del } \\
\text { cuento }\end{array}$ & Títeres & $20 \mathrm{~min}$ & Psicopedagogo \\
\hline & $\begin{array}{l}\text { Salten como las ranas, } \\
\text { que gateen y así } \\
\text { diferentes ejercicios que } \\
\text { permita que los niños se } \\
\text { relajen. }\end{array}$ & & & \\
\hline Diagnóstico & $\begin{array}{l}\text { Se les presentará a los } \\
\text { niños } 4 \text { cartillas con } \\
\text { imágenes, las cuales } \\
\text { siguen una secuencia de } \\
\text { una actividad. Los niños } \\
\text { tendrán que ordenarla. }\end{array}$ & cartillas & $10 \min$ & \\
\hline $\begin{array}{l}\text { Desarrollo del } \\
\text { tema } \\
\text { lectura coral }\end{array}$ & $\begin{array}{l}\text { El facilitador realizará } \\
\text { una lectura de una } \\
\text { leyenda, la lectura la } \\
\text { realizaran todos al } \\
\text { mismo tiempo, para } \\
\text { luego realizar un } \\
\text { análisis de todo lo que } \\
\text { ocurrió en el cuento. }\end{array}$ & cuento & $10 \mathrm{~min}$ & \\
\hline Aplicación & $\begin{array}{l}\text { Se volverá a presentar a } \\
\text { los niños cartillas en un } \\
\text { mayor número, donde } \\
\text { los niños en un } \\
\text { determinado grupo } \\
\text { arman la secuencia de la } \\
\text { historia. }\end{array}$ & cartillas & $10 \mathrm{~min}$ & \\
\hline Evaluación & $\begin{array}{l}\text { Se evaluará si los niños } \\
\text { lograron ordenarlas } \\
\text { imágenes en secuencia } \\
\text { correcta del para luego } \\
\text { colocarlas de forma } \\
\text { ordenada en el rincón de } \\
\text { cuentos }\end{array}$ & Hilo, pegamento & $10 \mathrm{~min}$ & \\
\hline
\end{tabular}




\section{Rico teatral 6}

Cuadro 9. Identificando la secuencia de los hechos ocurridos de un texto mediante las imágenes

\begin{tabular}{|c|c|c|c|c|}
\hline Actividades & Descripción & Materiales & Tiempo & Responsable \\
\hline Actuando & $\begin{array}{l}\text { Se les dará una } \\
\text { pequeña obra a } \\
\text { los niños de los } \\
\text { tres cerditos y el } \\
\text { lobo feroz y se } \\
\text { les repartirá } \\
\text { cada personaje, } \\
\text { para que los } \\
\text { niños actúen de } \\
\text { acuerdo al } \\
\text { personaje, y } \\
\text { siguiendo la } \\
\text { secuencia del } \\
\text { cuento. } \\
\text { Anticipadamente } \\
\text { se llevará todo } \\
\text { tipo de disfraces } \\
\text { para que los } \\
\text { niños actúen y } \\
\text { creen a su } \\
\text { personaje para la } \\
\text { actuación. }\end{array}$ & $\begin{array}{l}\text { Caja de } \\
\text { disfraces y, } \\
\text { obra y } \\
\text { guiones }\end{array}$ & $30 \mathrm{~min}$ & Psicopedagogo \\
\hline
\end{tabular}




\section{Rincón visual 7}

Cuadro 10. Realizan comentarios sobre el contenido del texto a partir de la imagen central del cuento.

\begin{tabular}{cllll}
\hline Actividades & \multicolumn{1}{c}{ Descripción } & Materiales & Tiempo & Responsable \\
\hline $\begin{array}{c}\text { Observando } \\
\text { aprendo }\end{array}$ & $\begin{array}{l}\text { Se proyectará } \\
\text { imágenes de }\end{array}$ & Dvd, cuento & 20 min & Psicopedagogo \\
& cuentos & & \\
& llamativos para & & \\
& todos los niños, & & \\
& de la cual cada & & \\
& niño mencionará & & \\
& en base a la & & \\
& imagen de que & & \\
& podría tratar el & & \\
& cuento. Después & & \\
& de que cada niño & & \\
& de su opinión se & & \\
& presentará el & & \\
& cuento. Esta & & \\
& actividad se & & \\
& puede repetir & & \\
& con cuentos que & & \\
& muestran los & & \\
& valores entre & & \\
& otros & & \\
\end{tabular}

\section{Rincón visual 8}

Cuadro 11. Realización de opiniones y preguntas sobre lo leído

\begin{tabular}{cllcc}
\hline Actividades & \multicolumn{1}{c}{ Descripción } & Materiales & Tiempo & Responsable \\
\hline $\begin{array}{c}\text { Observando } \\
\text { aprendo }\end{array}$ & $\begin{array}{l}\text { Se proyectará un } \\
\text { cuento sobre la } \\
\text { inclusión de }\end{array}$ & Dvd, cuento & 20 min & Psicopedagogo \\
& $\begin{array}{l}\text { personas con } \\
\text { discapacidad a }\end{array}$ & & \\
& las escuelas de la & & \\
& cual los niños & & \\
& realizarán & & \\
& opiniones y se & & \\
& les realizará \\
& preguntas acerca \\
& de lo visto. & & \\
\hline
\end{tabular}




\section{Rincón del cuento 9}

Cuadro 12. Lectura en voz alta y lectura silenciosa

\begin{tabular}{|c|c|c|c|c|}
\hline Actividades & Descripción & Materiales & Tiempo & Responsable \\
\hline $\begin{array}{l}\text { Leer el texto, } \\
\text { variando la } \\
\text { intensidad según } \\
\text { el tamaño de las } \\
\text { letras }\end{array}$ & $\begin{array}{l}\text { Se le entregará a cada niño un } \\
\text { cuento breve, donde las letras } \\
\text { sean grandes y pequeñas. Se les } \\
\text { explicará que si las letras son } \\
\text { grandes la leerán lo más fuerte } \\
\text { que puedan, si es una letra } \\
\text { pequeñita la leerán en voz baja. }\end{array}$ & Cuento & $20 \min$ & Psicopedagogo \\
\hline Leyendo en silencio & $\begin{array}{l}\text { Para finalizar con todo el taller } \\
\text { educativo se le entregará a cada } \\
\text { niño un cuento breve, y se les } \\
\text { pedirá que lo lean en silencio. } \\
\text { Para luego realizar preguntas } \\
\text { de retención espontánea, } \\
\text { retención guiada y la inferencia. }\end{array}$ & Cuento & $20 \mathrm{~min}$ & Psicopedagogo \\
\hline
\end{tabular}

\section{DISCUSIÓN}

\section{Definiciones teóricas acerca de la estrategia didáctica}

Brenes, (2003) define a la estrategia didáctica como "El cumplimiento y el propósito de ofrecer al educador diferentes recursos didácticos para el trabajo escolar y para el desarrollo del currículo con un enfoque centrado en los procesos de aprendizaje". (p.11).

En esta definición el autor hace hincapié en que la estrategia didáctica tiene como objetivo proponer distintos recursos didácticos, colaborativos, métodos y selección de actividades para el aprendizaje, siendo así que estas actividades planteadas por el autor irán dirigidas a lograr los objetivos, metas propuestos en base a las diferentes actividades que se planteen en la elaboración del currículo ya sean a lo largo o corto plazo sobre las diferentes etapas de aprendizaje escolar.
Sartori y Castilla (2014) definen lo siguiente:

La estrategia didáctica hace
alusión a una planificación del
proceso de enseñanza y
aprendizaje, de manera consciente
y reflexiva, en relación a las
técnicas y actividades que pueden
utilizarse para llegar a la meta
propuesta para un determinado
grupo clase. (p. 267).

Las autoras afirman que las estrategias didácticas son la planificación de un proceso de enseñanza y aprendizaje que hacen que el profesor conozca, dirija y domine la realización de las estrategias didácticas que ayudaran a mejorar elauto-aprendizaje de los alumnos, que deben ser de manera consciente y reflexiva en relación a las actividades que se planteen para alcanzar la meta dentro del proceso de enseñanza y aprendizaje. 
Por su parte Hernández, (1999) define la estrategia didáctica como "las grandes herramientas con la que cuenta la maestra y el niño y la niña (de cualquier edad y nivel escolar). Acuden en su ayuda cuando tienen que comprender un texto, adquirir conocimiento, resolver un problema, participar y aprender."(p. 71).

En esta definición la autora menciona que las estrategias didácticas son herramientas para los profesores quienes deben tomar distintas decisiones de manera consciente y reflexiva para la selección de técnicas y actividades para dirigir el aprendizaje de los alumnos hacia los objetivos deseados de cualquier nivel educativo y un contexto determinado, que les permite adquirir conocimientos, participar y aprender logrando así un aprendizaje eficaz para los niños y niñas Uría, (2001) define a la estrategia didáctica como "el análisis desde el trabajo del profesor, que es quien las utiliza de manera consciente para promover el aprendizaje" (p. 14).

El autor define que la estrategia didáctica se da por el análisis, la elección de actividades elegidas por el profesor o asesor quien definirá las actividades y técnicas que serán planificadas de acuerdo con las necesidades de la población, quien lo utilizara de manera consciente con la finalidad de facilitar el aprendizaje es sus alumnos y hacer más efectivo el proceso de aprendizaje.

Brenes, (2003) señala que la estrategia didáctica debe formar parte del educador debido a este puede utilizar y adecuar en el contexto escolar, muchos recursos valiosos para el descubrimiento, reflexión e integración de las actividades que promuevan el desarrollo físico, moral, social, cultural, además del intelectual, un ambiente agradable e interesante.

Por lo que se interpreta que el como la adecuación de diferentes actividades que irán a promover actividades en el proceso de enseñanza y aprendizaje para el cual el docente es quien elige las técnicas $\mathrm{y}$ actividades que favorezcan el desarrollo físico, moral, cultural e intelectual, creando un ambiente favorable y alcanzar los objetivos propuestos.

Hernández, (1999) define que "las estrategias didácticas se identifican con un conjunto de actividades que facilitan el aprendizaje, crean el clima para un aprendizaje dinámico, profundo, funcional en la vida y, por ello, significativo para el niño y la niña" (p. 71).

En esta definición la autora menciona que las estrategias didácticas son un conjunto de actividades que fortalecen, facilitan el aprendizaje reflexivo, creativo y permite la adquisición de conocimientos nuevos y habilidades de los alumnos por lo que la aplicación de estrategias didácticas son esenciales, ya que por medio de estas estrategias los estudiantes desarrollan la interacción y la adquisición de un eficiente desarrollo del aprendizaje, para todo niño y niña que cursa un proceso de aprendizaje de cualquier nivel educativo es necesario crear métodos, estrategias de aprendizaje.

Después del análisis realizado de las diferentes definiciones de estrategia didáctica, las cuales son esenciales para la investigación, se asumió una definición del autor Brenes, (2003) define que la estrategia didáctica es aquel donde él facilitador 0 educador puede adecuar mediante el contexto escolar y las características de los niños, realizando actividades de integración que promuevan el desarrollo intelectual, social, cultural y físico creando para los niños y niñas un ambiente favorable de aprendizaje e interacción, para cada niño de diferentes niveles educativos, siendo así que una estrategia didáctica debe ser una planificación creativa y reflexiva, donde los profesores u otro 
profesional logre crear métodos que permita adquirir conocimientos nuevos.

Analizado las diferentes definiciones planteadas por los autores, se describe la estructuración de la estrategia didáctica.

CONCLUSIONES

La lectura comprensiva es la relación entre la información almacenada y la nueva información que producirá el texto leído, logrando identificar los sucesos y las secuencias del cuento recuperando objetivos, ideas, valorizar la información y seleccionar la información que se encuentran ocultos en los diferentes textos.

La lectura comprensiva para los niños suele ser de poco interés, porque lo ven complicada, los métodos repetidos causan desinterés lo que hace que los niños no desarrollen la lectura comprensiva, no razonen y no comprendan lo que leen, no logran alcanzado el nivel de comprensión de acuerdo a su edad, demostrando dificultades al momento de comprender una lectura.

Los niños saben de la importancia que tiene comprender un cuento una historia una fábula para su educación, pero no se interesan por practicar la lectura y comprenderla, no se encuentran motivados, no cuentan con métodos variados que permita que los niños tengan un aprendizaje significativo.

\section{REFERENCIAS}

Betancourt, A. (2007). El taller educativo. Bogotá: EDITORIAL MAGISTERIO

Brenes, 0. (2003). Estrategias didácticas. Costa Rica: Universidad de Costa Rica

Gervilla, A. (2006). Didáctica básica de la Educación Infantil. España: Narcea

González, T. (2005). Comprensión lectora en niños morfosintaxis y prosodia en acción. Granada: Universidad de Granada

Hernández, M. (1999). Mediación en El Aula Recursos, Estrategias y Técnicas Didácticos. Costa Rica: EUNED

Sartori, L., y Castilla, M. (2014). Educar en la diversidad. Buenos Aires: Facultad de Filosofía Humanidades y Artes

Soto, L. (2013). Orientaciones para la elaboración de las Programaciones Didácticas. España: Vasco

Uría, E. (2001). Estrategias didácticoorganizativas para mejorar los Centros educativos. Madrid: Narcea, S.A. Ediciones 